\title{
Using Water Energy for Electrical Energy Conservation by Building of Micro hydroelectric Generators on The Water Pipelines That Depend on The Difference in Elevation
}

\author{
Engineer Mohammed Taih Gatte, Engineer Rasim Azeez Kadhim, Engineer Farhan Leftah Rasheed \\ Ministry of Science and Technology, Babylon, Iraq \\ Email: m_taih@yahoo.com
}

\section{Abstract:}

In this research we study the elevations of cities and the water resources specially at the dams reservoirs and the distance between them(dams \& cities), we use the Google Earth program to determine these elevations and calculate the difference between the average level (elevation) of water at the dam and the average level of cities, which we want to supply it by water, in order to save electrical power by using the energy of supplied water through pipe line from dams to the cities, the pressure of supplied water must be calculated from the difference in elevations(head). The saving of energy can be achieved by two ways. The first is the energy saving by reduce the consumed power in the pumping water from river, which is used for different purposes. The second is the hydroelectric power generated by establishing a micro hydroelectric generator on the pipe line of the water supplied.

Keyword: mini hydroelectric, micro hydroelectric, pipeline, head, flow rate, dam, elevation.

\section{INTRODUCTION}

Since the time of Babylonian and ancient Egypt, people have used the energy in flowing water to operate machinery and grind grain and corn. However, hydropower had a greater influence on people's lives during the 20th century than at any other time in history. The energy of flowing water is the most readily available, renewable and clean source of electricity. The hydraulic power is one of the oldest energy forms of mankind, namely used for irrigation and industry. Nowadays, small hydro is one of the most valuable answers to the question of how to offer to isolated rural communities the benefits of electrification and of progress, as well as to improve the quality of life [1].

Hydropower played a major role in making the wonders of electricity a part of everyday life and helped spur industrial development. Hydropower continues to produce 24 percent of the world's electricity and supply more than 1 billion people with power. The definition of micro hydropower varies in different countries and can even included systems with a capacity of a few megawatts[2].

\section{MICRO-HYDRO POWER PLANT}

Micro-hydro is a proven cost effective renewable energy system. If you have access to a reliable flow of water, it should be an option you consider. The energy of running water is harnessed by a turbine and converted to electricity. The amount of energy can be produced depends on water pressure (measured in terms of "head" or the vertical distance from the water take-off point down to the turbine), and volume, (measured as "flow" in gallon per minute). Low head systems require large water flows, and low flow systems require a high head to produce the same 
amount of hydropower. As little as 100 gallons per minute (gpm) falling 10 feet through a pipe, or 5 gallons per minute falling 200 feet through a pipe, can supply enough power to comfortably run a small household. Our small AC hydroelectric units use induction generators and are designed to operate isolated from the grid[1] [2].

The amount of power can be calculated by the following equation:-

Power $=0.18 \mathrm{hQE}$ watt

Where "h" the dynamic head in feet, "Q" the amount of water flow in gpm, "E" the efficiency of the turbine/generator combination.

The combined efficiency of the turbine and generator ranges from $40 \%$ to $80 \%$, with higher efficiency at higher heads and for larger generators. To get a rough idea, use 0.50 (representing 50\%) as a multiplier for efficiency [1][2].

\section{WATER PIPELINE}

Most hydro turbines require at least a short run of pipe to bring the water to the machine, and some turbines require piping to move water away from it. The length can vary widely depending on the distance between the source and the turbine. The pipeline's diameter may range from 1 inch to 1 foot or more, and must be large enough to handle the design flow. Losses due to friction need to be minimized to maximize the energy available for conversion into electricity. Plastic in the form of polyethylene or PVC is the usual choice for home-scale systems. Burying the pipeline is desirable to prevent freezing in extremely cold climates, to keep the pipe from shifting, and to protect it from damage and ultraviolet (UV) light degradation [2].
A hydroelectric turbine operates from the pressure at the bottom end of a pipeline. This pressure, usually measured in pounds per square inch (PSI), is directly related to the head. The pressure at the lowest point of a pipeline is equal to 0.433 times the head in feet. Pressure is important because it is a determining factor in how much power is available and what type of pipe is required. Polyethylene pipe can be used for pressures up to 100 PSI, PVC pipe is available with pressure ratings from 160 to 350 PSI and steel pipe can withstand 1000 PSI or more. Pipe diameter is very important. All pipelines will cause the water flowing in them to lose some energy due to friction. The pipe must be large enough for the maximum quantity of water it will carry. The pressure at the bottom of a pipeline when water is not flowing is called static pressure. When water is flowing through the outlet or nozzle of the hydroelectric turbine, the pressure at the outlet is the dynamic pressure or running head. If you install a gate valve on the pipeline just above the turbine and a pressure gauge on a " $\mathrm{T}$ " fitting just above the gate valve, you will read the static pressure on the gauge when the valve is closed and the dynamic pressure when the valve is opened. The maximum power that can be delivered by a pipeline will occur when the dynamic pressure is approximately $2 / 3$ of the static pressure. The actual flow rate of the water in a hydroelectric system is determined by the diameter of the nozzle[1][2][3].

\section{RESULTS \& CONCLUSIONS}

In this research we study and calculate the elevation of water at the dams in the whole country such as (Hadeetha, Samara, Diala, Hindia, Kufa and Abasia) and the elevation of the middle and south province center (Baghdad, Basra, Babylon, Kut, Nasria, Missan, and Samawa), by using the Google Earth program and then calculate the difference in elevation. Figure (1) shows the map of the region of our study. 


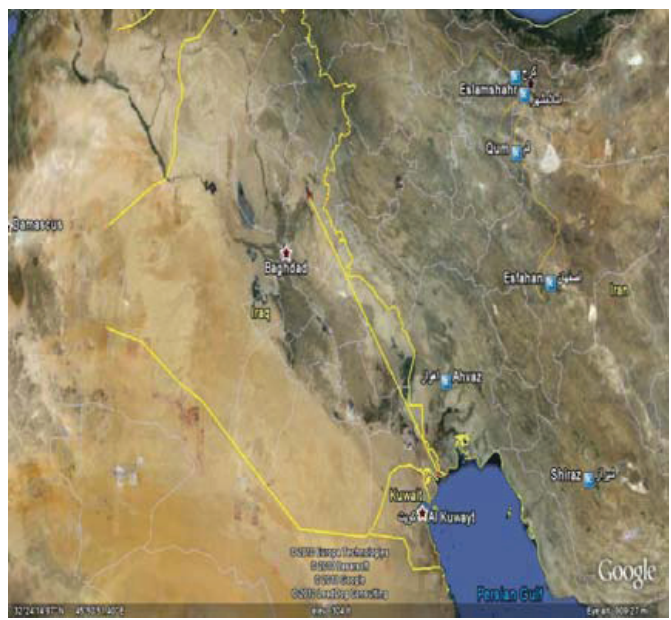

Figure (1) The map of the region of study

The concentration of our study was on Basra because it suffer from the lack of fresh water that suitable for the everyday using because the high ratio of salts in the water that arrive to the city through Tigris\& Euphrates rivers. In addition to the other cities problems that can be faced with the continuous reduction in the arrived quantity of water to the country, and the increasing in pollution levels of these rivers in the future. Where the expected pollution levels will cross over the permition level at which the processing of water become more difficult that the traditional water station can reach it.

\begin{tabular}{|c|c|c|c|c|c|c|c|}
\hline \multicolumn{8}{|c|}{$\begin{array}{l}\text { Table(1) Hadeetha dam with respect to Basra city } \\
\text { Head }=400 f, \text { Distance }=466 \text { mile, Sys. Efficiency } \\
=50 \%, Q=\text { flow rate(in gpm), } D=\text { pipe line diameter(in } \\
\text { inch), Po/p }=\text { power output(in } \mathrm{KW} \text { ), EPM }=\text { Energy } \\
\text { per month(in } \mathrm{KWH})\end{array}$} \\
\hline \multicolumn{3}{|c|}{$\begin{array}{l}\text { static (at no flow) } \\
\text { head loss }=80 \mathrm{ft}\end{array}$} & & \multicolumn{4}{|c|}{$\begin{array}{l}\text { dynamic(at design flow) } \\
\text { head loss }=100 \mathrm{ft}\end{array}$} \\
\hline $\mathbf{Q}$ & D & Po/p & EPM & & D & Po/p & EPM \\
\hline 1000 & 30 & 28.8 & 20736 & & 28 & 36 & 25920 \\
\hline 2000 & 39 & 57.6 & 41472 & & 37 & 72 & 51840 \\
\hline 3000 & 45 & 86.4 & 62208 & & 43 & 107 & \begin{tabular}{|l|l|}
77760 \\
\end{tabular} \\
\hline 4000 & 50 & 115.2 & 82944 & & 48 & 144 & \begin{tabular}{|l|l|}
103680 \\
\end{tabular} \\
\hline 5000 & 55 & 144 & 103680 & & 52 & 180 & \begin{tabular}{|l|l}
129600 \\
\end{tabular} \\
\hline 6000 & 59 & 172.8 & 124416 & & 56 & 216 & 155520 \\
\hline 7000 & 62 & 201.6 & 145152 & & 59 & 252 & \begin{tabular}{|l|l|}
181440 \\
\end{tabular} \\
\hline 8000 & 65 & 230.4 & 165888 & & 62 & 288 & \begin{tabular}{|l|l}
207360 \\
\end{tabular} \\
\hline 9000 & 68 & 259.2 & 18662 & & 65 & 324 & \begin{tabular}{|l|}
233280 \\
\end{tabular} \\
\hline 10000 & 71 & 288 & 207360 & & 68 & 360 & \begin{tabular}{|l|l}
259200 \\
\end{tabular} \\
\hline
\end{tabular}

From the results shown in the tables below we see that in table(1) the difference in elevation(head) between Basra city and Hadeetha dam is $400 \mathrm{ft}$ and the distance is 466 mile approximately. To supply the city by 1000 gpm we need a pipeline with 28 inch diameter or more, and to supply the city by $10000 \mathrm{gpm}$ the pipeline of 68 inch diameter or more can be used.

These pipeline can produce a hydroelectric power from $36 \mathrm{KW}$ to $360 \mathrm{KW}$ which can save an energy from $25920 \mathrm{KWH}$ to $259200 \mathrm{KWH}$ per month, in addition to the power saving, through the way of supplying water with high pressure by using a pipeline, which will consumed in the case of lifting that quantities of water from the river at the destination point to the water station or for any other using of water.

Table(2) shows the difference in elevation(head) between Basra city and Diala dam is $290 \mathrm{ft}$ and the distance is 341 mile approximately. To supply the city by $1000 \mathrm{gpm}$ we need a pipeline with 28 inch diameter or more, and to supply the city by $10000 \mathrm{gpm}$ the pipeline of 68 inch diameter or more can be used.

\begin{tabular}{|c|c|c|c|c|c|c|}
\hline \multicolumn{7}{|c|}{ Table(2) Diala dam with respect to Basra city } \\
\hline \multicolumn{7}{|c|}{$\begin{array}{l}\text { Head }=290 \mathrm{ft}, \text { Distance }=341 \text { mile Sys. Efficiency } \\
=50 \%, Q=\text { flow rate(in gpm), } \mathrm{D}=\text { pipe line diameter(in } \\
\text { inch), Po/p = power output(in } \mathrm{KW}), \mathrm{EPM}=\text { Energy per } \\
\text { month(in } \mathrm{KWH})\end{array}$} \\
\hline \multicolumn{4}{|c|}{$\begin{array}{l}\text { static (at no flow ) } \\
\text { head loss }=58 \mathrm{ft}\end{array}$} & \multicolumn{3}{|c|}{$\begin{array}{l}\text { dynamic (at design flow) } \\
\text { head loss }=73 \mathrm{ft}\end{array}$} \\
\hline $\mathbf{Q}$ & D & Po/p & EPM & D & $\mathbf{P o} / \mathbf{p}$ & EPM \\
\hline 1000 & 30 & 20.9 & 15034 & 28 & 26.1 & 18792 \\
\hline 2000 & 39 & 41.8 & 30067 & 37 & 52.2 & 37584 \\
\hline 3000 & 45 & 62.6 & 45101 & 43 & 78.3 & 56376 \\
\hline 4000 & 50 & 83.5 & 60134 & 48 & 104.4 & 75168 \\
\hline 5000 & 55 & 104.4 & 75168 & 52 & 130.5 & 93960 \\
\hline 6000 & 59 & 125.3 & 90202 & 56 & 156.6 & 112752 \\
\hline 7000 & 62 & 146.2 & 105235 & 59 & 182.7 & 131544 \\
\hline 8000 & 65 & 167 & 120269 & 63 & 208.8 & 150336 \\
\hline 9000 & 68 & 187.9 & 135302 & 65 & 234.9 & 169128 \\
\hline 10000 & 71 & 208.8 & 150336 & 68 & 261 & 187920 \\
\hline
\end{tabular}


These pipelines can produce a hydroelectric power from $26.1 \mathrm{KW}$ to $261 \mathrm{KW}$, which can save an energy from $18792 \mathrm{KWH}$ to $187920 \mathrm{KWH}$ per month in.

Table(3) shows the difference in elevation(head) between Basra city and Abasia dam is $70 \mathrm{ft}$ and the distance is 260 mile approximately. To supply the city by $1000 \mathrm{gpm}$ we need a pipeline with 36 inch diameter or more, and to supply the city by $10000 \mathrm{gpm}$ the pipeline of 86 inch diameter or more can be used.

\begin{tabular}{|c|c|c|c|c|c|c|}
\hline \multicolumn{7}{|c|}{$\begin{array}{l}\text { Table (3) Abasia dam with respect to Basra city } \\
\text { Head }=70 \mathrm{ft} \text {, distance }=\mathbf{2 6 4 . 0 9} \text { mile, Sys. efficiency }=50 \%, \mathrm{Q}= \\
\text { flow rate(in gpm), } \mathrm{D}=\text { pipe line diameter(in inch), Po/p }= \\
\text { power output(in } \mathrm{KW} \text { ), EPM = Energy per month(in } \mathrm{KWH})\end{array}$} \\
\hline \multicolumn{4}{|c|}{$\begin{array}{l}\text { static (at no flow) } \\
\text { head loss }=14 \mathrm{ft}\end{array}$} & \multicolumn{3}{|c|}{$\begin{array}{l}\text { dynamic (at design flow) } \\
\text { head loss }=18 \mathrm{ft}\end{array}$} \\
\hline $\mathbf{Q}$ & D & Po/p & EPM & D & $\mathrm{Po} / \mathbf{p}$ & EPM \\
\hline 1000 & 38 & 5.04 & 3629 & 36 & 6.3 & 4536 \\
\hline 2000 & 49 & 10.1 & 7258 & 47 & 12.6 & 9072 \\
\hline 3000 & 57 & 15.1 & 10886 & 55 & 18.9 & 13608 \\
\hline 4000 & 64 & 20.2 & 14515 & 61 & 25.2 & 18144 \\
\hline 5000 & 70 & 25.2 & 18144 & 66 & 31.5 & 22680 \\
\hline 6000 & 75 & 30.2 & 21773 & 71 & 37.8 & 27216 \\
\hline 7000 & 79 & 35.3 & 25402 & 76 & 44.1 & 31752 \\
\hline 8000 & 83 & 40.3 & 29030 & 79 & 50.4 & 36288 \\
\hline 9000 & 87 & 45.4 & 32659 & 83 & 56.7 & 40824 \\
\hline 10000 & 90 & 50.4 & 36288 & 86 & 63 & 45360 \\
\hline
\end{tabular}

These pipelines can produce a hydroelectric power from $6.3 \mathrm{KW}$ to $63 \mathrm{KW}$, which can save an energy from $4536 \mathrm{KWH}$ to $45360 \mathrm{KWH}$ per month

Figure (1) below shows the relations between the flow rate in gpm with pipeline diameter in inch that represent the quantity of water supplied to the Basra city from the dams (Hadeetha, Diala, Hindia, Abasia). The one who see this relations utilize that the graph of Hadeetha dam and Diala is complying in spite of the difference in the dams head, because the difference in the distances, where long distance causes high friction loss ,so that to decrease this friction loss the pipeline diameter must be large, and the same thing shown for Abasia and Hindia dams.

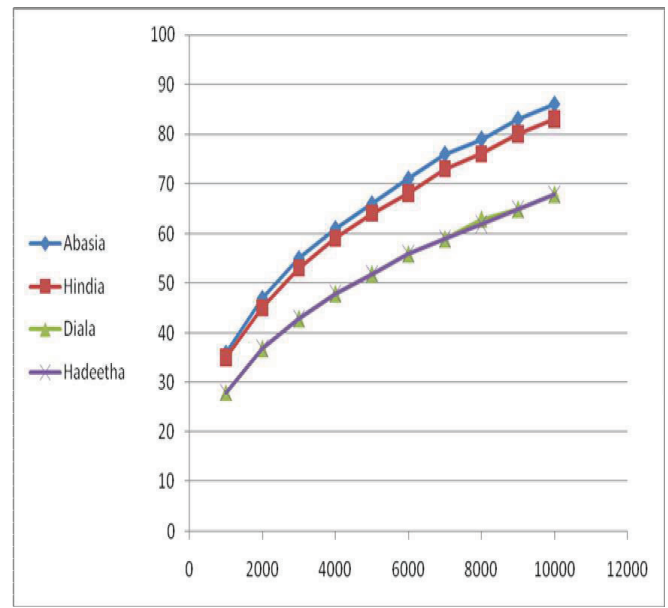

Figure (1) The Relation Between Flow Rate (Q) in gpm and Pipeline Diameter in inch For Supplying Water to Basra City from Dams

Figure (2) below shows the relations between the flow rate in gpm that represent the quantity of water supplied to the Basra city from the dams (Hadeetha, Diala, Hindia, Abasia) with the hydroelectric generated power in KW. The idea behind this graph is that the slopes of the lines increase with the increasing of head at the dams, so that the hydro generated power from Hadeetha dam is the higher and the lower power from Abasia dam for the same quantity of the flow rate (Q) gpm.

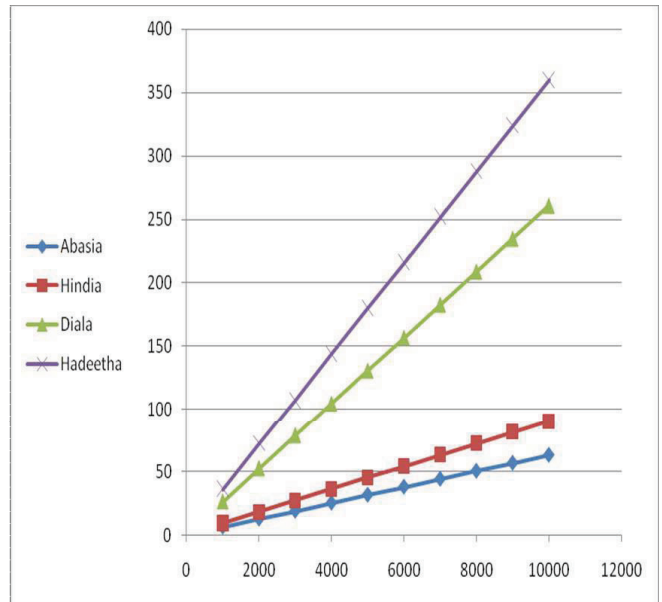

Figure (2) The Relation Between Flow Rate (Q) in gpm and The Hydroelectric Generated power in KW From Supplying Water to Basra City from Dams 
From all the above, if the one need to adopted this study to execute or establishing a project of water pipelines and a micro \& mini hydroelectric generators, which need to a further studying about cost calculations and the obstacles or difficulties that may be faced him, because this is a theoretical study and the practical project will require a solution to a practical problems that the pipe lines intersect it, like mount, river, villages, ....etc.

\section{REFRENCES:}

1. Helena RAMOS and A. Betamio de ALMEIDA - "Small HydroPower Schemes as an Important Renewable Energy Source", Technical University of Lisbon, Portugal.

2. http// www. nooutage.com, hydroelectric information, December 2008.

3. Helena RAMOS and A. Betamio de ALMEIDA - "Small HydroPower as One of The Oldest Renewable Energy Sources", Technical University of Lisbon, Portugal.

4. European Small Hydropower Association (ESHA), "Guide on How to Develop a Small Hydropower Plant", 2004.

5. Omar, MD Mabulu and N Dlakavu, "Feasibility of Micro-Hydropower in The Western Cape", Peninsula Technikon, Bellville, South Africa, Domestic Use of Energy Conference 2003.

6. Jessica G. Kirchhoffer and Philip C. Malte, "Balancing Energy Options in Stehekin, Washington", University of Washington, 2003.

7. Brian B. Yanity, "Cold Climate Problems of a MicroHydroelectric Development on Crow Creek", The Arctic Energy Summit, Anchorage, Alaska $2007-2008$. 